\title{
THINKING ABOUT TIME AS MONEY DECREASES ENVIRONMENTAL BEHAVIOR
}

\author{
by \\ Ashley Victoria Whillans \\ B.A. Hons., University of British Columbia, 2012

\begin{abstract}
A THESIS SUBMITTED IN PARTIAL FULFILLMENT OF THE REQUIREMENTS FOR THE DEGREE OF
\end{abstract} \\ MASTER OF ARTS \\ in
}

The Faculty of Graduate and Postdoctoral Studies

(Psychology)

THE UNIVERSITY OF BRITISH COLUMBIA

(Vancouver)

August 2014

(C) Ashley Victoria Whillans, 2014 


\begin{abstract}
Despite high profile environmental campaigns, Americans are no more likely to engage in environmental behavior today than they were 20 years ago. A novel explanation for this paradox may lie in the increasing tendency for people to see their time as money. National survey data suggests that seeing time as money is related to decreased environmental behavior. Using large-scale survey data (Study 1), we show that people are less likely to engage in environmental behavior if they are paid by the hour, a form of compensation that leads people to see their time as money. Using experimental methodology, we show that making the economic value of time salient lowers intentions to engage in environmental behavior (Studies $2 \& 3$ ) and actual recycling (Study 4). In Study 4, students led to see their time as money were five times less likely to recycle scrap paper when given the opportunity. In Study 5, we document a mechanism for this effect - individuals who are paid by the hour are chronically aware of the opportunity costs associated with engaging in everyday environmental behavior. Together, this research suggests that environmental decisions are shaped by viewing time as money, potentially shedding light on patterns of environmental behavior across time and around the world.
\end{abstract}




\section{PREFACE}

I am the primary author of the work presented in this thesis. I was responsible for designing the experiments and for collecting, analyzing, and interpreting the data. A version of this thesis has been submitted for publication: Whillans, A.V. \& Dunn, E.W. Thinking about time as money decreases environmental behavior. This research was conducted with the permission of the University of British Columbia Office of Research Studies Behavioral Research Ethics Board, certification number H12-02356, "Daily Habits \& Behavior.” 


\section{TABLE OF CONTENTS}

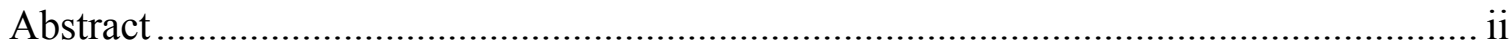

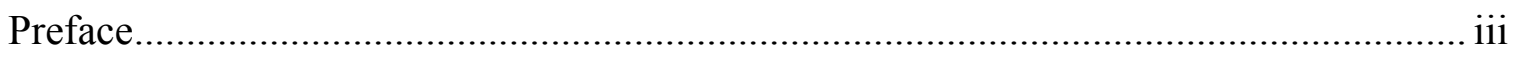

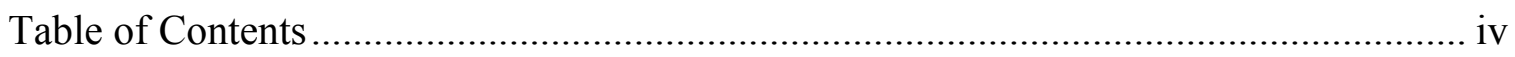

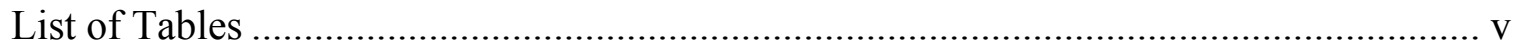

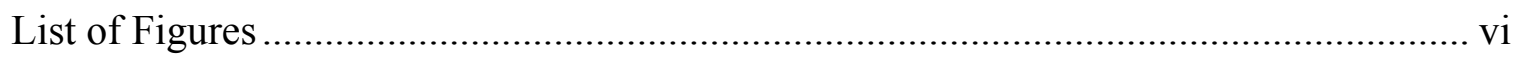

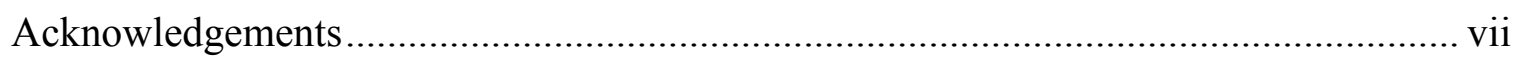

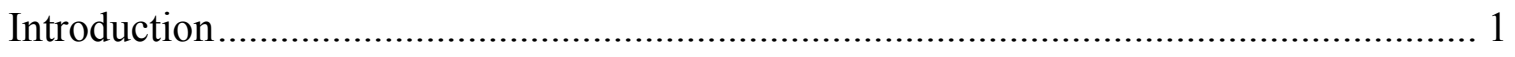

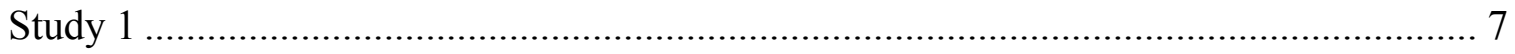

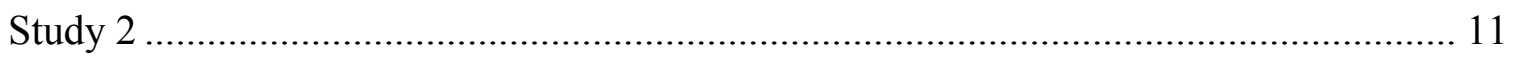

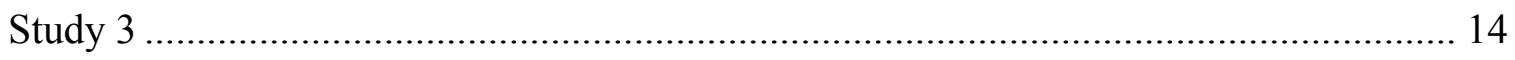

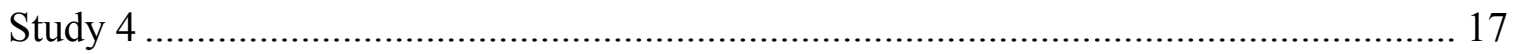

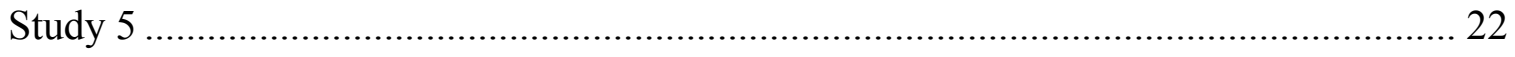

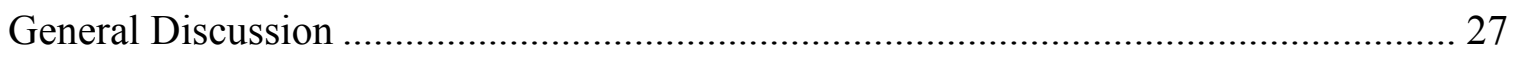

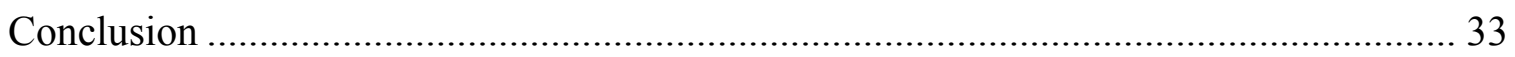

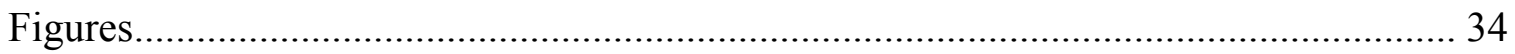

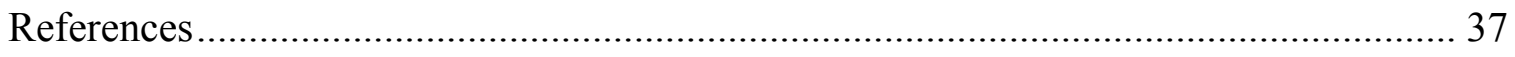

Appendix 1: BHPS Scale Items \& Variable Names .................................................... 43

Appendix 2: Supplementary Materials and Results................................................ 44

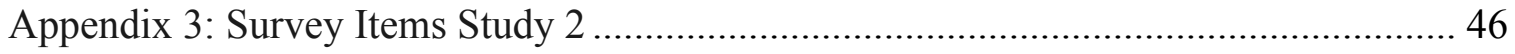

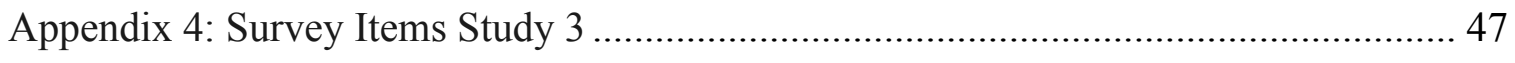

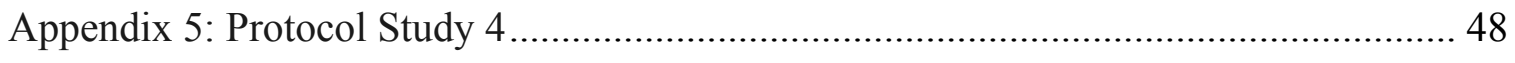

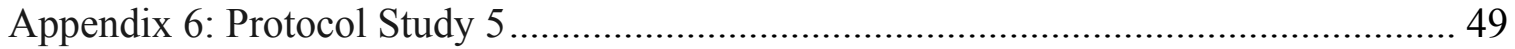




\section{LIST OF TABLES}

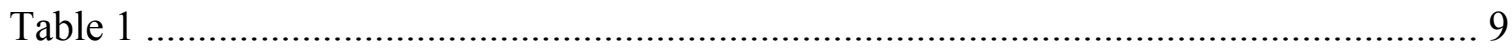

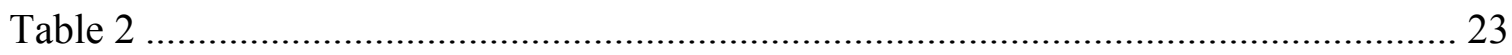

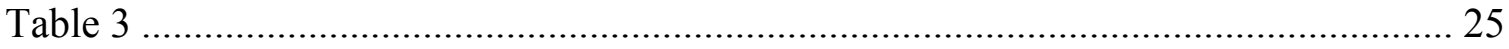

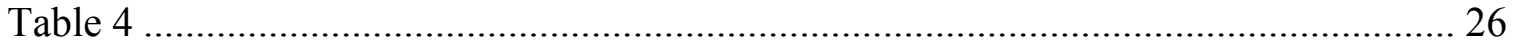




\section{LIST OF FIGURES}

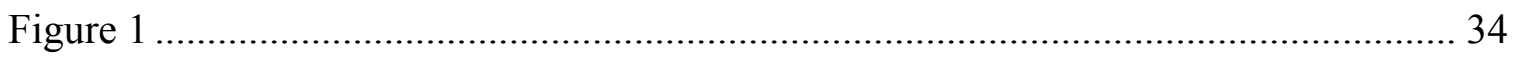

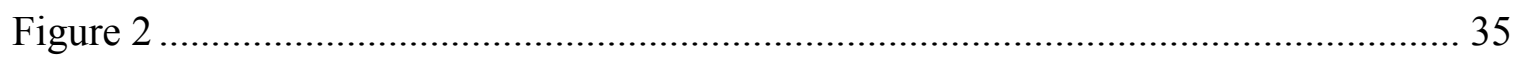

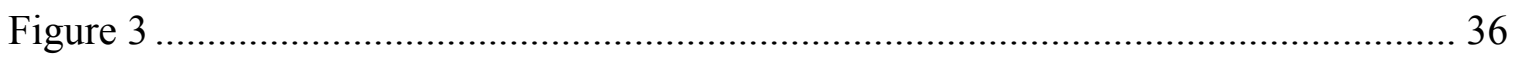




\section{ACKNOWLEDGMENTS}

I would like to thank my adviser Dr. Elizabeth Dunn for her guidance and support throughout my undergraduate and graduate studies. I would also like to thank my committee for their time and insight, as well as other professors that have provided invaluable mentorship throughout my degree, including Dr. Frances Chen for enriching my graduate school experience, Dr. Sanford DeVoe for instrumental advice, Dr. Eugene Caruso for helpful feedback and encouragement, and Dr. Lara Aknin for an infectious love of research that initially inspired my decision to pursue graduate studies. Thank you to my wonderful parents and boyfriend (now fiancé!) that have supported my academic and non-academic aspirations. Finally, thank you to the research assistants that made this thesis possible: Sarah, Shirley, Amy, Jenny, Nathan, Juan, Lizy, and Katie. If I have the good fortune of having my own lab one day, cancel your plans; I'm taking you with me! 


\section{INTRODUCTION}

Americans are no more likely to engage in environmental behavior today than they were 20 years ago (Morales, 2010). One surprising explanation for the stagnation of environmental behavior may lie in the increased value that individuals place on their time. Although the number of hours people work has remained relatively constant over the last five decades (Aguiar \& Hurst, 2009), Americans report feeling that their time is more valuable than ever before (Carroll, 2008). Research suggests that being paid by the hour leads people to see their time as financially valuable (DeVoe \& Pfeffer, 2007), and the proportion of the workforce paid by the hour increased significantly in the 1980's and 1990's (Hamermesh, 2002) maintaining these gains through 2012 (Bureau of Labor Statistics, 2013). A growing body of research demonstrates that reminding people how much money their time is worth can have far-reaching effects on the decisions they make about their time (DeVoe \& Pfeffer, 2010), pointing to a novel explanation for the limited impact of environmental campaigns on environmental behavior. In light of this research, we sought to investigate whether thinking about time as money would decrease engagement in everyday environmental behaviors.

\section{Thinking about Time as Money}

A great deal of research supports the assertion that thinking about time as money changes the way that individuals view and use their time (e.g., DeVoe, Lee \& Pfeffer, 2010; DeVoe \& Pfeffer, 2010; DeVoe \& Pfeffer, 2007). National survey and experimental research suggests that individuals who are paid by the hour devalue noncompensated activities, and are more willing to give up their free time to earn money (DeVoe \& Pfeffer, 2007). Field research suggests that employees who bill their hours 
become economic evaluators of their time, thereby making time related decisions using economic criteria as opposed to considering social obligations or personal satisfaction (Evans, Kunda \& Barley, 2004; Kaveny, 2001; Yakura, 2001). Similarly, national survey research suggests that hourly-wage workers are chronically oriented to think of their time as money, leading them to devalue uncompensated activities and to spend less time volunteering (DeVoe \& Pfeffer, 2007).

Consistent with the notion that thinking about time as money can have farreaching effects on thoughts and behavior, simply asking people to calculate their hourly wage in the lab decreases willingness to volunteer without compensation (DeVoe \& Pfeffer, 2007; 2010). This research suggests that thinking about time as money alters the way that individuals view their time, leading individuals to devalue non-compensated activities, and to spend less time volunteering their time for free. However, volunteering often carries a significant time cost, which might seem particularly unappealing when time is seen as money. Going beyond past research, we propose that environmental behaviors — even those that require mere moments to complete, such as recycling —might also be affected by thinking about the monetary value of one's time.

\section{Thinking about Time as Money and Environmental Behavior}

Why would putting an economic value on time undermine environmental behavior? One potential explanation put forth in the literature is that billing time leads market pricing to become salient (Pfeffer \& DeVoe, 2009). This claim is supported by experimental research showing that when individuals are paid for their labor, they adjust their efforts in direct relation to the amount of compensation that they have received for the activity (Heyman \& Ariely, 2004). These findings imply that if market-pricing 
thought processes are invoked when thinking about time as money, people will expend less effort and time engaging in activities for which there is no direct compensation.

If thinking about time as money decreases engagement in non-compensated and time costly activities such as volunteering, why might thinking about time as money decrease engagement in relatively non-time costly activities? We suggest that thinking about time as money activates the component of an individual's motivational system associated with self-enhancing values (Pfeffer \& DeVoe, 2009). This prediction is derived from research demonstrating that reminding individuals how much their time is worth can make money-related concepts more relevant to the self, leading individuals to focus on their own needs and goals as opposed to the needs and goals of others (Pfeffer \& DeVoe, 2009; Vohs, Mead \& Goode, 2006; 2008). This shift toward self-enhancing values may help to explain why thinking about time as money could decrease engagement in relatively non-time costly environmental behaviors such as recycling.

Specifically, research on the structure of values suggests that values are organized in a circumplex fashion, whereby certain values and goals are psychologically consistent with one another, and other values and goals stand in conflict with one another. Relevant to our research, Shalom Schwartz's classic work on human values demonstrates that “community" values, which entail trying to help others outside of one's own in-group, stand in stark opposition to values related to "power" and "achievement" (Schwartz 1977; 1992; 2009). For example, research has demonstrated that the value of financial success is 192 degrees in opposition to values related to community, with 180 degrees representing perfect opposition (Grouzet et al., 2005). In an experimental demonstration of this phenomenon, individuals primed with statements related to financial success were 
less likely to help others during an in lab task (Maio et al., 2009). Together with work showing that reminders of money reduce engagement in prosocial behaviors (Vohs, Mead \& Goode, 2006; 2008), these studies suggest that there is a motivational conflict between values related to money and values supportive of prosociality.

Together, this research suggests that thinking about time as money may result in the suppression of the self-transcendent component of an individual's motivational system that allows individuals to focus on the needs of others. Researchers have argued that this ability to focus on others is a necessary condition for both prosocial and proenvironmental behavior (Allen \& Ferrand, 1999; Geller, 1995; Schwartz, 1977). Thus, based on this literature, we propose that thinking about time as money, which may lead individuals to desire compensation for their work, and to prioritize personal goals, will decrease engagement in everyday environmental behaviors. Past research in this area has primarily examined the effects of thinking about time as money on volunteering. Our research seeks to expand the conceptualization of what thinking about time as money affects, by examining the effect of thinking about time as money on minimally time costly and non-compensated activities (e.g., environmental behaviors).

\section{Overview of the Present Research}

In summary, the purpose of the present research is twofold: (1) to examine the novel question of whether thinking about time as money decreases environmental intentions and behavior, and (2) to expand the conceptualization of what time as money alters in terms of psychological and behavioral consequences. To address these questions, we employed national panel survey data, lab experiments, and a field study. Given the novelty of establishing a causal link between thinking about time as money and 
environmental behavior, it is important to triangulate across different methodologies and populations (e.g., Mathison, 1988). This is particularly important given that students work and earn less than the general population, and have experiences with time and money that differ from the general public (Ford, Bosworth \& Wilson, 2006).

In addition, lab and online experiments may not generalize to behavior outside of such sterile, controlled environments (Harrison \& List, 2004; Levitt \& List, 2007). Consequently, we examined the relationship between thinking about time as money and environmental behavior in a nationally representative survey, several lab studies with college students, and a paper and pencil study conducted in the field with working adults. By triangulating across our methodologies and by using both college and non-college students, we are able to explore how thinking about time as money affects the proclivity to engage in environmental behavior among a broad range of individuals.

\section{The Present Research}

To provide an initial test of our hypothesis, we analyzed data from a large-scale, nationally representative survey (Study 1). We then investigated the causal relationship between thinking about time as money and intentions to engage in environmental behavior (Study 2). Because reminders of money can lead individuals to prioritize their own needs and goals over the needs and goals of others (Vohs, Meade \& Goode, 2006; 2008), we further hypothesized that thinking about time as money would decrease intentions to engage in environmental behavior but would not decrease intentions to exercise, an uncompensated and self-beneficial activity (Study 3). In Study 4, we moved beyond self-report to examine whether seeing one's time as money would decrease the likelihood of recycling, a prototypical form of environmental behavior. Next, we sought 
to explore a potential mechanism for this effect - the spontaneous recognition of the opportunity costs associated with environmental behavior (Study 5). By exploring the effect of thinking about time as money on minimally time costly environmental behaviors, and by exploring whether thinking about time as money decreases engagement in self-beneficial activities, this research seeks to expand the conceptualization of what time as money alters in terms of psychological and behavioral consequences.

Across these studies, we follow the reporting standards proposed by Simmons, Nelson \& Simonsohn (2011) to maximize transparency: we report the decision rule regarding each sample size, all data exclusions, the results with and without data exclusions, every condition that was run and every measure that was given. Due to the changing norms in our field, we pre-registered the hypothesis of Study 5 and rewrote the consent form to enable us to post the data from this study online (osf.io/p $7 \mathrm{xme}$ ); data from our earlier studies are available upon request. 


\section{STUDY 1}

In Study 1, we analyzed data from a publicly available data set to examine how hourly-wage payment and environmental behavior relate in a nationally representative sample of adults.

\section{Method}

Participants. In Study 1, we analyzed data from Wave 18 of the British Household Panel Survey (BHPS). The British Household Panel Survey was established in 1999 at the University of Essex. The purpose of the survey is to further understanding of social and economic change at the individual and household level in Britain. The BHPS is a nationally representative sample consisting of over 5,000 British households, and approximately 10,000 individual interviews of adults 16 years of age and above.

We analyzed the most recent wave of the BHPS (Wave 18), as this was this first wave that included measures of both hourly-wage status and environmental behavior. Because past research shows that individuals who are paid by the hour are more likely to see their time as money (DeVoe \& Pfeffer, 2007, 2010), we predicted that hourly (vs. salaried) workers would report engaging in fewer environmental behaviors.

Measures. Respondents reported whether or not they were paid by the hour (4128 respondents were salaried and 2802 were paid hourly), as well as how often they typically engage in eight pro-environmental behaviors, which we averaged to create an index of engagement in environmental behavior $(\alpha=.67$; See Appendix 1 for BHPS survey items and variable names). Participants answered these questions on a 1-5 scale ranging from $1=$ Always to $5=$ Never; we reverse-scored the items such that positive coefficients would represent greater self-reported engagement in environmental behavior. 
In addition to the frequency category responses, another valid response to these items was "I cannot do this," and this response was re-coded to missing in our analyses. ${ }^{1}$

Covariates. We used the same set of covariates as previous research on the effects of hourly versus salaried payment (monthly income, number of hours worked, marital status, age, education, and number of children and other people in the home; DeVoe, Lee \& Pfeffer, 2010). We also controlled for gender given the robust finding that women are more likely to engage in environmental behavior (Zelezny, Chua \& Aldrich, 2000).

\section{Results and Discussion}

First, we wanted to explore whether hourly-wage workers reported decreased selfreported engagement in environmental behavior. We obtained an average score for participants on self-reported frequency of engagement in environmental behavior. ${ }^{2} \mathrm{We}$ used this average score to conduct a regression analysis between hourly-wage status $(0=$ Non-hourly, $1=$ Hourly $)$ and self-reported engagement in environmental behavior.

As predicted, hourly (vs. salaried) workers reported less frequent engagement in environmental behaviors, $r(6930)=-.08, p<.001, \mathrm{CI}_{95}[-.13,-.07]$. This relationship held after controlling for our set of covariates, $\beta=-.06, p<.001, \mathrm{CI}_{95}[-.11,-.04]$ (Table 1).

\footnotetext{
${ }^{1}$ Results are significant with and without setting this response category to missing. 2 The sample sizes for the bivariate survey linear regressions on each item vary slightly due to differing numbers of respondents who reported having no ability to control the behaviors examined by these items. The proportion of the BHPS sample of all individuals paid an hourly or salary wage that reported being able to engage in each of the eight environmental behaviors varied between 95\% ("Buys recycled products") and $99.999999 \%$ ("Switches off lights in empty rooms"). In total, valid scale scores that included all eight items were obtained from $98.78 \%$ of the sample.
} 
Table 1. Predicting environmental behavior from hourly-wage status and covariates.

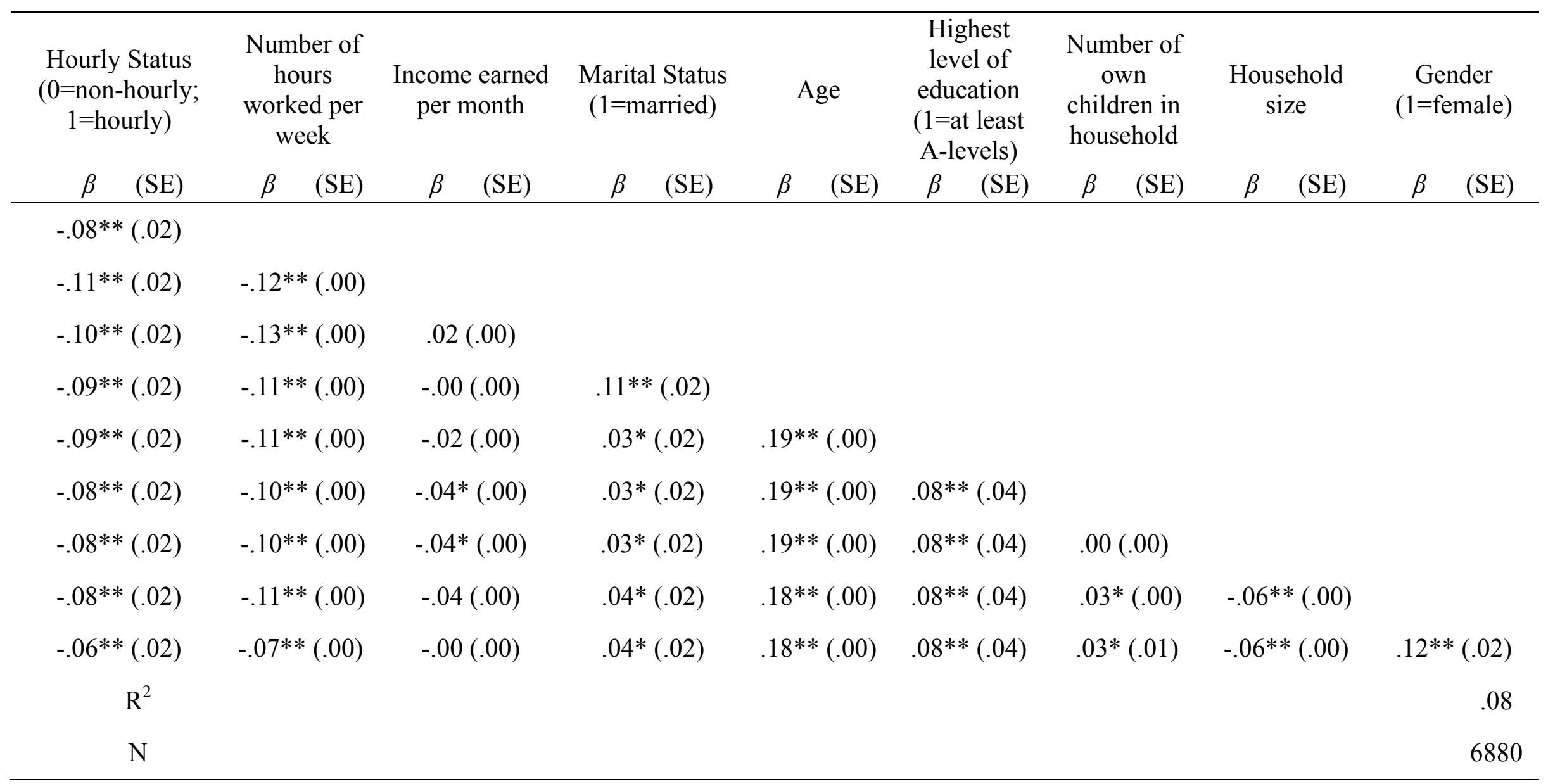

Note. Environmental items were reverse coded so that positive coefficients represented greater self-reported environmental behavior.

$$
\begin{aligned}
& \dagger p<.10 \\
& * p<.05 \\
& * * p<.001
\end{aligned}
$$




\section{Summary of Results}

In Study 1, we found initial support for the hypothesis that thinking about time as money is associated with reduced engagement in everyday acts of environmental behavior. While these results are consistent with our hypothesis, the correlational nature of these data precludes causal claims. For example, these findings could be explained by an unmeasured third variable in our data set such as personal values. A great deal of research suggests that personal values shape career decisions, with individuals choosing professions that match their own values and goals (e.g., Bretz \& Judge, 1992). It is plausible then that individuals who pursue professions that involve billing time such as law or accounting fundamentally differ in their prioritization of environmental issues compared to individuals who pursue salaried professions, such as teaching or medicine.

To rule out this and other potential explanations, and to better understand the relationship between thinking about time as money and environmental behavior, we conducted an experiment investigating whether making the economic value of time salient would decrease intentions to engage in environmental behavior. 


\section{STUDY 2}

Study 2 was designed to investigate the causal association between thinking about time as money and environmental intentions using a lab experiment.

\section{Method}

Participants. We chose a target sample size of approximately 200 participants based on prior research using an identical manipulation (Pfeffer \& DeVoe, 2009). We succeeded in recruiting 193 undergraduates at the University of British Columbia (UBC) in exchange for course credit. Nine participants failed to complete our manipulation due to confusion ( 5 in the experimental condition and 4 in the control condition), leaving a total of 184 participants $\left(77.6 \%\right.$ female; $\left.M_{\text {age }}=19.68, S D=2.39\right) .^{3}$

Procedure. After providing informed consent, participants were randomly assigned to an hourly-wage or control condition. Next, participants reported their intentions to engage in environmental behaviors and rated the worthwhileness of these behaviors (in that order). Participants then completed additional measures tangential to the present hypothesis (Appendix 2), provided demographic information, and completed items assessing suspicion. No participant guessed the hypothesis of the study, thus the suspicion items are not discussed further.

Hourly-wage Manipulation. In the hourly-wage condition, participants completed three questions about expected income during their first year after graduation. Participants reported how many hours they would work per week, how many weeks they would work per year, and their expected income the year following graduation. All participants then used this information to complete an identical calculation. In the

\footnotetext{
${ }^{3}$ Our critical results are robust to the inclusion/exclusion of these participants, $p s<.05$.
} 
experimental condition, participants were informed that they had just calculated their future hourly wage - a technique that has been used in past research to make the economic value of one's time salient (DeVoe \& Pfeffer, 2007). In the control condition, participants were not informed that they had just calculated their future hourly wage. Thus, the key component of this manipulation is that participants across both conditions complete identical calculations of time and money, yet only participants in the hourlywage condition are explicitly asked to think about their own time as money.

\section{Measures.}

Environmental Intentions. All participants rated the likelihood that they would engage in 14 environmentally beneficial behaviors during their first year after graduation, such as reusing ziplock bags and paying bills electronically (adapted from the Ecologically Responsible Behavior Questionnaire; 1-Never to 7-Always; $\alpha=.68$; Brown \& Kasser, 2005; See Appendix 3 for scale items).

Perceived Worth. Participants also reported the worthwhileness of engaging in each of these environmental behaviors their first year after graduation (1-Not at all Worthwhile to 7-Very Worthwhile; $\alpha=.82$ ).

\section{Results and Discussion}

As predicted, participants in the hourly-wage condition reported reduced intentions to engage in environmental behavior $(M=4.79, S D=.79)$ compared to participants in the control condition $(M=5.01, S D=.72), F(1,183)=3.85, p=.05, \eta^{2}=$ $.02, \mathrm{CI}_{95}[-.44,-.00]$. Participants in the hourly-wage condition reported that engaging in these behaviors was less worthwhile $(M=5.06, S D=.86)$ than participants in the control condition $(M=5.37, S D=.89), F(1,183)=5.67, p=.02, \eta^{2}=.03, \mathrm{CI}_{95}[-.56,-.05]$. 


\section{Summary of Results}

Study 2 demonstrates that thinking about time as money decreases intentions to engage in environmental behavior and makes these behaviors seem less worthwhile. It is possible, however, that participants in the hourly-wage condition may have been disinclined toward environmental behaviors due to an enhanced concern with the financial costs of these behaviors (Liu \& Aaker, 2008). Therefore, we asked a separate group of 70 students to rate each of the 14 environmental behaviors on a scale from -5 (costs money) to +5 (saves money). Only two of these behaviors (buying local and buying organic) were rated as significantly negative from a cost perspective, and all of our critical effects remained significant when these items were eliminated from the scale.

Additionally, it is possible that participants led to think about their time as money might be less interested in engaging in all unpaid activities. Consequently, in Study 3 we examined the effects of thinking about time as money on intentions to exercise. Like environmental behavior, exercise is an unpaid and socially desirable activity, but unlike engaging in environmental behavior, exercise primarily benefits the individual.

Consistent with research suggesting that thinking about time as money might lead individuals to focus on one's own needs and goals as opposed to the needs and goals of others (Pfeffer \& DeVoe, 2009; Vohs, Mead \& Goode, 2006, 2008), we predicted that making the economic value of time salient would reduce intentions to engage in environmental behavior, but would not reduce intentions to exercise. 


\section{STUDY 3}

In Study 3, we examined the relationship between thinking about time as money and intentions to engage in environmental behavior as well as the relationship between thinking about time as money and intentions to exercise. We predicted that thinking about time as money would decrease environmental intentions, but not intentions to exercise.

\section{Method}

Participants. Based on the effect sizes from Study 2, we conducted a power analysis and determined that we needed 434 participants for $95 \%$ power (GPower, 2013). To allow for attrition based on our manipulation, we recruited 454 students to participate for course credit. Nineteen participants (4\%) failed to complete the manipulation due to confusion (10 in the experimental conditions and 9 in the control conditions), leaving a total of 435 participants $(77.6 \%$ females; Mage $=19.99, S D=2.60) .{ }^{4}$

Procedure. Participants were assigned to either a future hourly-wage or control condition, using identical procedures from Study 2. Then, half the participants were assigned to complete the same environmental measures used in Study 2, including rating how often they would engage in 14 environmental behaviors following graduation. The other half were asked to rate the likelihood that they would engage in 14 exercise behaviors following graduation (e.g., "taking the stairs at work or school;" $\alpha=.67$ ) and rated the worthwhileness of these behaviors ( $\alpha=.80$ : See Appendix 4 for scale items).

\section{Results and Discussion}

Intentions. There was a marginally significant interaction between hourly-wage condition and behavior (i.e., exercise or environmental) to predict intentions, $F(1,433)=$

\footnotetext{
${ }^{4}$ The effect of hourly-wage payment on environmental intentions remained marginally significant in the predicted direction including these participants in our analyses, $p=.12$.
} 
$2.63, p=.11, \eta^{2}=.01, \mathrm{CI}_{95}[-1.09,-.76]$. Consistent with the findings of Study 2 , participants in the hourly-wage condition reported reduced intentions to engage in environmental behavior $(M=5.27, S D=.81)$ compared to participants in the control condition $(M=5.47, S D=.68), F(1,223)=4.27, p=.04, \eta^{2}=.02, \mathrm{CI}_{95}[-.43,-.02]$. Furthermore, consistent with our prediction, participants in the hourly-wage condition did not report reduced intentions to exercise $(M=4.48, S D=.94)$ compared to participants in the control condition $(M=4.42, S D=1.02), F(1,220)=.23, p=.63$.

Perceived Worth. There was no evidence of an interaction between hourly-wage condition and behavior to predict perceived worth, $F(1,433)=.01, p=.93$. In contrast to our hypothesis, participants in the hourly-wage condition did not report that environmental behavior was less worthwhile $(M=4.84, S D=.69)$ compared to participants in the control condition $(M=4.87, S D=.66), F(1,223)=.10, p=.76$.

\section{Summary of Results}

Consistent with the possibility that thinking about time as money leads individuals to focus on personal pursuits, asking participants to calculate their future hourly-wage reduced intentions to engage in environmental behavior but did not reduce intentions to exercise. Whereas in Study 2 we saw that thinking about time as money decreased the worthwhileness of these behaviors, in Study 3 we did not replicate this effect. We discuss possible explanations for this discrepancy in the general discussion. Given that the interaction between the hourly-wage and behavior conditions did not reach conventional levels of significance, these results should be interpreted with caution.

Because there is a great deal of research suggesting that behavioral intentions do not necessarily translate into action (Webb \& Sheeran, 2006), in Study 4 we sought to 
replicate our central finding using a behavioral outcome. We examined paper recycling because it is one of the most widely adopted forms of environmental behavior and is neutral with respect to costing or saving money. 


\section{STUDY 4}

In Study 4, we assigned participants to think about their time as money and provided participants with the opportunity to recycle their scrap paper during a lab task. Our hypothesis was that participants who were led to think about their time as money would be less likely to recycle compared to participants in our control condition.

\section{Method}

Participants. We recruited sixty UBC students to participate in a study for course credit; we selected this sample size based on previous research using a similar manipulation to affect behavior in the lab (Pfeffer \& DeVoe, 2010). One participant did not complete the manipulation due to experimenter error, five participants failed to complete the manipulation due to confusion, and two participants reported not hearing about the option to recycle, leaving a total of 52 participants $(73.1 \%$ females; $M=20.18$, $S D=2.27)^{5}$

Procedure. Participants were assigned to an hourly-wage or control condition using identical procedures from Studies 2 and 3. Participants were told that they would complete a series of tasks, one of which involved cutting out shapes from construction paper (adapted from Catlin \& Wang, 2013). The experimenter mentioned that participants could discard the paper in a trash bin inside the room or a recycling bin just outside the room (Appendix 5 for protocol). Our measure of environmental behavior was whether participants chose to walk a few extra feet to recycle their scrap paper. Participants then completed questionnaires including identical ancillary measures from Study 2, demographics, and suspicion items. None of the participants guessed the true

\footnotetext{
${ }^{5}$ Our critical results are robust to the inclusion of these participants, $p<.04$.
} 
purpose of the experiment, therefore these suspicion items are not discussed further.

Recycling Protocol. We adapted our recycling protocol from recently published research (Catlin \& Wang, 2013; Evans et al., 2013). To avoid suspicion, the experiment was presented as a series of tasks, the first of which involved filling out a questionnaire (our manipulation), the second of which involved the use of paper. After completing the manipulation, participants were given three pieces of construction paper, one pencil, one pair of scissors, and three shape tracers. In line with our cover story, we first asked participants if they were right or left-handed. Participants were then instructed to cut a small and a large version of each shape, and to dispose of their scrap paper in a trash bin or recycling bin upon completion of the task.

Consistent with past research, the trash bin was placed near where the participant was sitting just outside the participant's reach. The recycling bin was placed just outside the entrance of the lab room and thus was a more inconvenient choice for participants (Evans et al., 2013). It is important to note that although the recycling bin was placed further away, it did not take substantially longer to recycle compared to throwing out the scrap paper. When two research assistants reenacted these behaviors, it took the research assistants an average of 2.6 seconds to recycle vs. throw out the scrap paper.

Additionally, the recycling bin was not visible to participants in the hallway upon starting the study — it was placed in the hallway outside the lab room while participants were completing the shape-cutting task. The trash and the recycling bin had equivalent amounts of paper in them at the beginning of the experiment to avoid the influence of social norms in differentially influencing recycling decisions (Catlin \& Wang, 2013). The scrap paper that was used during the task was a darker color (grey) compared to the paper 
placed inside the trash and recycling bins (white). This detail enabled research assistants to confirm that participants had disposed of their scrap paper upon completing the task.

Finally, if the participant had not disposed of their scrap paper upon completion of the task, the research assistant reminded the participant to dispose of their scrap paper in the trash or the recycling. If this occurred, the research assistants were instructed to report to the participant that they had "forgotten" the final set of questionnaires for the study in an adjacent lab room, in order to allow for the participant to make their recycling decision alone. This situation occurred twice, and on neither occasion did the participants guess the true purpose of the experiment after being reminded of the instructions to dispose of their scrap paper in the trash or the recycling bin.

\section{Results and Discussion}

A chi-square revealed that fewer participants in the hourly-wage condition recycled their scrap paper upon completing the task (12.0\%) compared to participants in the control condition $(40.7 \%), \chi^{2}(1, N=51)=5.45, p=.02$. The odds ratio for the condition coefficient is 5.04 with a $95 \%$ confidence interval of $[1.21,21.06]$. Participants were five times less likely to recycle if they had calculated their future hourly-wage (Figure 1).

\section{Summary of Results}

As predicted, participants in Study 4 were less likely to recycle scrap paper after calculating their future hourly-wage. Given that lab experiments may not generalize to behavior outside of the lab (Harrison \& List 2004; Levitt \& List, 2007), we next wanted to extend our experimental research to a community sample of working adults, while investigating a psychological mechanism for this effect.

Research suggests that thinking about time as money makes people feel that their 
time is increasingly valuable (Pfeffer \& DeVoe, 2010). When people are led to feel that their time is valuable, they may become chronically aware of the time costs associated with everyday environmental behaviors. Study 4 provided evidence for this possibility. We found that thinking about time as money decreased recycling, despite the fact that the act of recycling took only three additional seconds to complete. In Study 5, we wanted to provide a direct test of the hypothesis that thinking about time as money increases the awareness of the costs associated with engaging in everyday acts of environmental behavior. We hypothesized that hourly workers might be chronically aware of the time costs associated with environmental behaviors.

When thinking about how to spend money, people typically overlook opportunity costs; for example, people may choose a $\$ 400$ phone over a $\$ 300$ phone without spontaneously considering what they could do with the $\$ 100$ they would save by buying the cheaper model (Frederick et al., 2009). Similarly, when thinking about how to spend time, individuals may fail to consider the other activities that they could do during the same period of time. However, there are individual differences in the extent to which individuals are chronically aware of opportunity costs: people who care about saving money readily consider the opportunity costs of purchasing decisions (Rick, Cryder \& Loewenstein, 2008; Frederick et al., 2009; Study 5). To the extent that hourly workers see the value of their time, they may recognize the time costs associated with environmental behavior. In contrast, salaried workers may not spontaneously recognize these time costs - unless they are provided with an explicit reminder. Thus, we expected that reminding individuals of the time costs associated with environmental behavior would have a greater impact on salaried (vs. hourly) workers, leading salaried workers to exhibit 
the same reluctance to engage in environmental behaviors that hourly workers exhibit by default. This prediction is consistent with research showing that manipulations designed to make the economic value of time salient exert the greatest influence on individuals who are not already paid by the hour (DeVoe \& Pfeffer, 2007). 


\section{STUDY 5}

In Study 5, we predicted that individuals who were paid by the hour would spontaneously consider the opportunity costs of environmental decisions. Therefore, we predicted that individuals who were paid by the hour would be unaffected by reminders that making an environmental choice would take time that they could spend doing something else. In contrast, we predicted that salaried workers would be less willing to make an environmental choice when they were reminded of the time-related opportunity costs associated with their decision.

\section{Method}

Participants. Based on the results from Studies 1-4, we assumed a small to medium effect size, and determined that we would need 141 participants for $95 \%$ power (GPower, 2013). Because we were only interested in studying individuals who were paid an hourly or salaried wage, we excluded unemployed, retired, or student respondents. To allow for exclusions on our a priori criteria, we recruited 188 adults from a public market in Vancouver, Canada who participated in our study for the chance to win $\$ 100$ in a lottery. In our sample, 61 respondents reported receiving a salaried wage and 70 respondents reported being paid by the hour, resulting in a total of 131 participants for our analyses $(55 \%$ females; $\mathrm{M}=33.57, \mathrm{SD}=12.83)$. Four participants failed to complete the dependent measure, thus the following results are based on 127 participants. On average, hourly-wage workers were significantly more likely to be female, were younger, and reported making less money compared to salaried workers, $p s<.001$ (See Table 2 on the following page). 


\begin{tabular}{cccc}
\hline & Hourly-wage & Salaried & Statistics \\
\hline \% of females & $72.1 \%$ & $27.9 \%$ & $X^{2}(1,123)=13.60 * * *$ \\
Age & $28.88(11.08)$ & $37.65(12.93)$ & $t(127)=4.10^{* * *}$ \\
Income & $5.54(4.61)$ & $8.53(4.19)$ & $t(125)=3.82 * * *$
\end{tabular}

Table 2. Mean differences between salaried and hourly-wage workers on gender, age, and income. Categories: $8=\$ 70,000-\$ 80,000$ and $5=\$ 40,000-\$ 50,000$. Note $* * * p<.001$.

Procedure. We first asked participants whether they were paid an hourly or salaried wage. All participants were then assigned to the opportunity-cost or to the control condition, and were asked to read one of two scenarios that involved an environmentally beneficial choice (Appendix 6). After indicating their decision, participants reported their age, gender, ethnicity, and annual household income, as well as an exploratory measure of environmental concern (Appendix 2).

Scenarios. In each scenario, participants were asked to imagine that they had learned about the positive impact that daily decisions can have for the environment (such as using a travel mug for their morning coffee). Participants were then faced with a hypothetical situation whereby it would take extra time to make the environmental choice that they had recently learned about. In the travel mug scenario, individuals were told that they had left their travel mug at home, which would take approximately five minutes to retrieve. To increase the generalizability of our results, we also used a second scenario, in which participants were told that they would miss the next bus home if they made the decision to recycle a soda can — which would increase their commute by approximately five minutes. Participants were then asked whether or not they would make the environmentally beneficial choice (e.g., return home to get their travel mug). 
Consistent with past research on opportunity cost neglect, we manipulated the saliency of time-related opportunity costs by randomly assigning participants to report their environmental decision using one of two response sets. In the opportunity cost condition, participants were asked if they would make the environmental choice, and were reminded that making the environmental choice would take time that they could spend doing something else (Figure 2). In the control condition, participants were asked if they would make the environmental choice, and were not reminded that they could spend this time doing something else (adapted from Frederick et al., 2009).

We predicted that individuals who were paid by the hour would spontaneously consider the opportunity costs associated with their decision, and would not be influenced by reminders of the opportunity costs associated with making the environmentally beneficial choice. In contrast, we predicted that individuals who were paid a salaried wage would be less likely to make the environmental choice when they were reminded of the time costs associated with the environmental decision.

\section{Results and Discussion}

Overall, $47 \%$ of participants made the environmental choice, comparable to rates of prosociality observed in other similar studies (Fowler \& Kam, 2007; Piff et al., 2010).

To predict the likelihood of making the environmental choice, we entered Payment $(0=$ Salaried, $1=$ Hourly $)$, Condition $(0=$ Control, $1=$ Opportunity Cost $)$, and a Payment X Condition interaction term into a binary logistic regression model $(0=\mathrm{No}$ Environmental Choice, 1=Environmental Choice). As expected, there was a significant interaction between Payment X Condition (Table 3). 


\begin{tabular}{lllllll}
\hline Predictor & $\boldsymbol{\beta}$ & SE $\boldsymbol{\beta}$ & Wald & Sig. & $\mathbf{e \beta}$ & $\mathbf{C I}$ \\
\hline Cost & .56 & .50 & 1.26 & .26 & 1.75 & {$[.66,4.65]$} \\
Hourly & 1.25 & .55 & 5.27 & .02 & 3.50 & {$[1.20,10.20]$} \\
Cost X & -1.68 & .74 & 5.23 & .02 & .19 & {$[.04, .79]$} \\
Hourly & & & & & & \\
Model & $\chi^{2}=6.65$ & $p=.08$ & & & & \\
Pseudo $\mathrm{R}^{2}$ & .07 & & & & & \\
$\mathrm{~N}$ & 127 & & & & & \\
\hline
\end{tabular}

Table 3. Logistic regression analysis of environmental choice with no covariates.

Follow-up analyses revealed that $39 \%$ of salaried workers in the opportunity cost condition made the environmental choice compared to $67 \%$ of salaried workers in the control condition, $\chi^{2}(1, \mathrm{~N}=60)=4.42, p=.04$. In contrast, the opportunity cost reminder had no impact on hourly-wage workers, $\chi^{2}(1, \mathrm{~N}=67)=1.27, p=.26$.

Consistent with our previous work, salaried workers were more likely to make the environmental choice in the control condition (67\%) compared to hourly-wage workers $(36 \%), \chi^{2}(1, \mathrm{~N}=60)=5.46, p=.02$, whereas this difference was eliminated in the opportunity cost condition, $\chi^{2}(1, \mathrm{~N}=67)=.76, p=.38$ (Figure 3 ).

Our critical results are statistically equivalent controlling for age, gender, and socioeconomic status (See Table 4 on the following page). 


\begin{tabular}{lllllll}
\hline Predictor & $\boldsymbol{\beta}$ & SE $\boldsymbol{\beta}$ & Wald & Sig. & $\mathbf{e} \boldsymbol{\beta}$ & $\mathbf{C I}$ \\
\hline Gender & .11 & .39 & .08 & .78 & 1.11 & {$[.52,2.40]$} \\
Age & .00 & .02 & .04 & .84 & 1.00 & {$[.97,1.04]$} \\
Income & -.04 & .05 & .74 & .39 & .96 & {$[.88,1.05]$} \\
Cost & .58 & .51 & 1.29 & .26 & 1.79 & {$[.66,4.89]$} \\
Hourly & 1.42 & .60 & 5.51 & .02 & 4.12 & {$[1.26,13.46]$} \\
Cost X & -1.60 & .75 & 4.54 & .03 & .20 & {$[.05, .88]$} \\
Hourly & & & & & & \\
Model & $\chi^{2}=6.41$ & $p=.09$ & & & & \\
Pseudo $\mathrm{R}^{2}$ & .07 & & & & & \\
$\mathrm{~N}$ & 123 & & & & & \\
\hline
\end{tabular}

Table 4. Logistic regression analysis of environmental choice with age, gender, and income as covariates. Note. $\mathrm{N}=4$ participants did not provide age, gender, or income information, thus these analyses are based on 123 of a possible 127 participants.

\section{Summary of Results}

Study 5 provides evidence that hourly-wage workers spontaneously consider the opportunity costs associated with environmental behavior. This increased awareness reduces hourly-wage workers' proclivity to engage in minimally costly behaviors, such as taking five minutes out of one's day to make an environmentally beneficial choice. By studying hourly vs. salaried workers outside of the lab, we show that thinking about time as money influences environmental decision-making among working adults. Consequently, this study documents a previously unexplored mechanism by which hourly-wage payment affects time-use: individuals paid by the hour are chronically aware of the trade-offs that they are making with every minute of their time. 


\section{GENERAL DISCUSSION}

The current research provides the first empirical evidence that thinking about time as money decreases environmental behavior. In a large, nationally representative sample of adults, individuals who were paid by the hour-making the economic value of time chronically salient—were less likely to engage in a broad range of environmental behaviors. In a sample of undergraduates, simply asking participants to calculate their own future hourly wage reduced participants' intentions to engage in environmental behavior. Importantly, thinking about time as money had no effect on intentions to exercise, an unpaid activity that primarily benefits the individual. These findings suggest that highlighting the economic value of time does not undermine willingness to engage in all unpaid activities. Moving beyond self-report, students were less likely to recycle paper after thinking about the economic value of their time. Next, we documented a potential mechanism for this effect—-hourly-wage compared to salaried workers appear to chronically recognize the trade-offs that they are making with their time, which may account for their decreased proclivity to spend five minutes helping the environment.

Consistent with previous research (DeVoe \& Pfeffer, 2007; 2010), these findings demonstrate that temporarily leading individuals to see their time as money produces acute effects that are consistent with chronic patterns of behavior exhibited by hourly workers. Our finding that people are less likely to engage in environmental behaviors when thinking about time as money provides a novel explanation for a vexing puzzle: Despite high profile campaigns, the adoption of everyday environmental actions has flatlined. In the US, hourly-wage payment has become more predominant, creating a previously unrecognized barrier to environmental behavior. 
It is worth noting that the effect sizes across our studies were small—which is unsurprising given research suggesting that numerous factors can influence environmental intentions and behavior. However, subtle changes in environmental behavior can translate into meaningful differences when multiplied by a large number of individuals (Prentice \& Miller, 1992). For example, if each of the 75 million hourly workers in the US recycled an additional pound of paper each year, this act alone would save 28 million trees (AFPA, 2010).

\section{Theoretical Contributions of this Research}

Our research adds to a growing body of literature documenting the impact of thinking about time as money on time-use attitudes and behavior. Critically, our research expands the conceptualization of what time as money alters in terms of psychological and behavioral consequences. First, our research provides the novel insight that thinking about time as money decreases engagement in prosocial behavior associated with relatively minimal time costs. Secondly, our research provides initial evidence that thinking about time as money decreases engagement in communal activities such as environmental behaviors without decreasing engagement in self-beneficial activities. Together these mechanisms suggest that when people are led to think about the economic value of their time, they become aware of the trade-offs that they are making with every minute and consequently may prioritize personal goals.

Correlational and experimental evidence suggests that thinking about time as money leads individuals to prioritize compensated activities over social and prosocial activities (DeVoe \& Pfeffer, 2007; Evans, Kunda, and Barley, 2004). However, this research has primarily focused on volunteering — which can take a substantial amount of 
time to complete, and might seem particularly unappealing when the economic value of one's time is salient. Our research extends past work by examining the effects of thinking about time as money on environmental behaviors that take a minimal amount of time to complete. In Study 4, participants were given the opportunity to recycle their scrap paper during an in lab task, an action that took participants an additional three seconds to complete compared to discarding their scrap paper in the trash. Similarly, in Study 5, we assessed the likelihood that participants would engage in an environmental act that takes five minutes (comprising $0.3 \%$ of an individual's time in a 24 hour period). These studies suggest that thinking about time as money decreases the proclivity to engage in prosocial behaviors that require only a minimal amount of time to complete.

When people are led to think about the economic value of their time, and feel their time is valuable, they may prioritize spending time in self-beneficial ways. To the best of our knowledge, our research is the first to explicitly test this hypothesis. In Study 4, participants asked to think about their time as money reported reduced intentions to engage in environmental behavior, but did not report reduced intentions to exercise. These findings are consistent with the idea that thinking about time as money decreases environmental behaviors in part because these behaviors are associated with transcendent values that oppose the economic values provoked by thinking about time as money.

\section{Limitations and Future Directions}

There are several limitations to the present research that warrant discussion. The first limitation is the external validity of the manipulations used in Studies 2-4. Asking participants to calculate their own future hourly-wage in the lab has been used in past research to make the economic value of time salient (DeVoe \& Pfeffer, 2007). It also 
enables us to provide an initial test of the effects of thinking about time as money on environmental intentions and behavior. However, this manipulation does not allow us to assess whether increasing the economic value of one's time systematically alters an individuals' likelihood of engaging in environmental behaviors over time.

It would therefore be worthwhile to conduct an experiment switching the payment schedules of lab employees, and to observe individual and group-level changes in environmental behavior, such as recycling. This type of experiment would enable us to assess the strength of our causal claim that thinking about time as money decreases individual environmental behavior, while simultaneously controlling for demographic variables that may influence the proclivity to think about one's time as money, as well as the likelihood of engaging in environmental behavior (e.g., gender).

We also saw mixed evidence regarding the extent to which thinking about time as money decreases the perceived worthwhileness of engaging in environmental behavior. In Study 2, we observed initial evidence that thinking about the economic value of one's time decreased the perceived worthwhileness of engaging in environmental behaviors. However, in Study 3, we did not replicate this effect. Given the results of Study 3, it is likely that perceived worth does not play a significant role in explaining the relationship between thinking about time as money and decreased environmental behavior.

Consistent with this possibility, it is unlikely that thinking about time as money decreases explicit beliefs about the importance of engaging in environmental behaviors. For example, our manipulations did not influence participants' feelings of environmental concern (Appendix 2), suggesting that thinking about time as money acts on implicit attitudes in order to decrease environmental intentions and behavior (Ajzen, 1991; 
Armitage \& Conner, 2001). Research suggests that when the costs of engaging in prosocial behavior are high, individuals are less likely to engage in these behaviors (Andreoni, Gale \& Scholz, 1996). Thus, future work should assess whether thinking about time as money influences environmental intentions and behavior by implicitly changing the perceived difficulty of completing such actions.

Another logical extension of this research would be to investigate the extent to which thinking about time as money decreases engagement in other relatively non-time costly prosocial behaviors. For instance, it would be worthwhile to examine whether thinking about the economic value of one's time decreases charitable giving when the charitable act has a seemingly negligible time cost (e.g., the donation involves putting a check in the mail or scrolling to the bottom of a webpage to place a donation). Such investigations would help charities more effectively target professionals who work in an organizational setting that promotes an orientation to think about time as money.

Ongoing research in our lab suggests that framing charitable giving as an act consistent with personal goals as opposed to common goals with others can increase donations to poverty relief charities among wealthy individuals (Whillans, Caruso \& Dunn, 2014). Similarly, if thinking about time as money leads individuals to prioritize self-interest, environmental organizations should include campaigns that focus on the self-related benefits of environmental behavior depending on their targeted clientele.

Relatedly, it would be worthwhile to ameliorate the negative effects of thinking about time as money on environmental behavior. As Study 5 suggests, reducing the perceived cost to the self or enhancing the perceived benefits for the self should overcome the detrimental effect of seeing time as money on environmental behavior. 
Indeed, ongoing research in our lab suggests that reminding individuals of the personal benefits of engaging in environmental behavior reduces the negative consequences of thinking about time as money on recycling behavior.

While the present research primarily sheds light on individual decision-making, this work can potentially provide novel insight regarding patterns of environmental behavior across time and around the world. Future research should examine whether changes in the economic value of time predicts global changes in environmental behavior. Although the proportion of Americans paid by the hour has increased, the proportion of hourly workers has remained relatively low in many European countries (Hamermesh, 2002). In a study of 17,000 consumers across 17 countries, Americans ranked lowest on the Consumer Greendex - an index reflecting the percentage of consumers who make sustainable consumer decisions, such as using paper bags as opposed to plastic (Greendex Index, 2012). In contrast, Europeans scored near the top of rankings among developed countries. National differences in the proportion of hourly workers might help to explain global differences in sustainable behavior. 


\section{CONCLUSION}

The current work demonstrates that thinking about time as money can decrease environmental intentions and actual environmental behavior. Extending previous research, this investigation suggests that thinking about time as money decreases engagement in relatively non-time costly behaviors by making the time costs of everyday environmental behavior chronically salient and by leading individuals to focus on their own needs and goals as opposed to the needs and goals of others. Future research should extend this research by examining the generalizability of these effects to other forms of prosocial behavior such as charitable giving. Future work should also explore the extent to which differences in the tendency to think about time as money might explain patterns of environmental behavior across time and around the world. Taken together, this research lays the foundation for understanding how thinking about time as money might provide a previously unexplored barrier to sustainable behavior. 
Figure 1. Percentage of participants choosing the recycling bin for each condition.

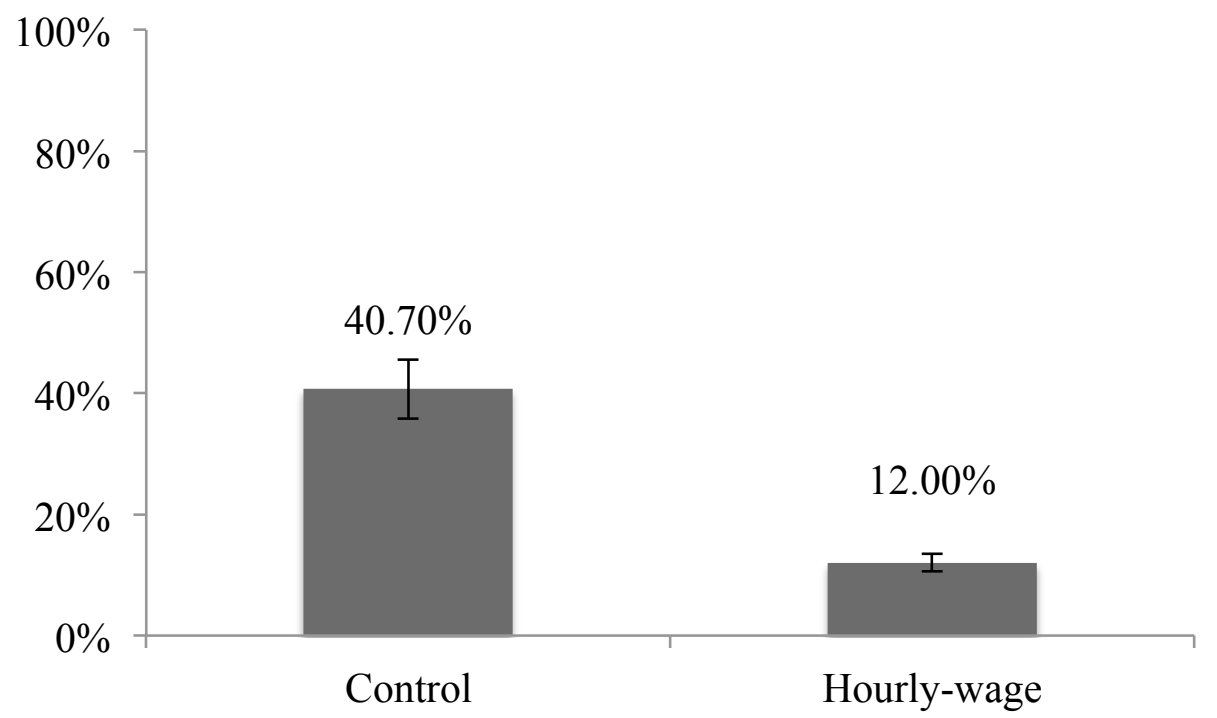


Figure 2. Opportunity Cost Condition

Imagine that you have recently listened to a radio program about the importance of everyday environmental behaviors. This radio program reminded you about a simple daily action that can help the environment, using a travel mug versus a disposable cup for your favorite morning beverage (e.g., coffee). You have purchased a travel mug, but after leaving the house this morning, you realize that you have left your travel mug at home (which is about a 5 minute walk away).

What would you do? Please circle one of the options below.

A) Return home to get your travel mug

B) Do not return home to get your travel mug [Spend this 5 minutes doing something else]. 
Figure 3. Logistic regression analysis predicting environmental choice.

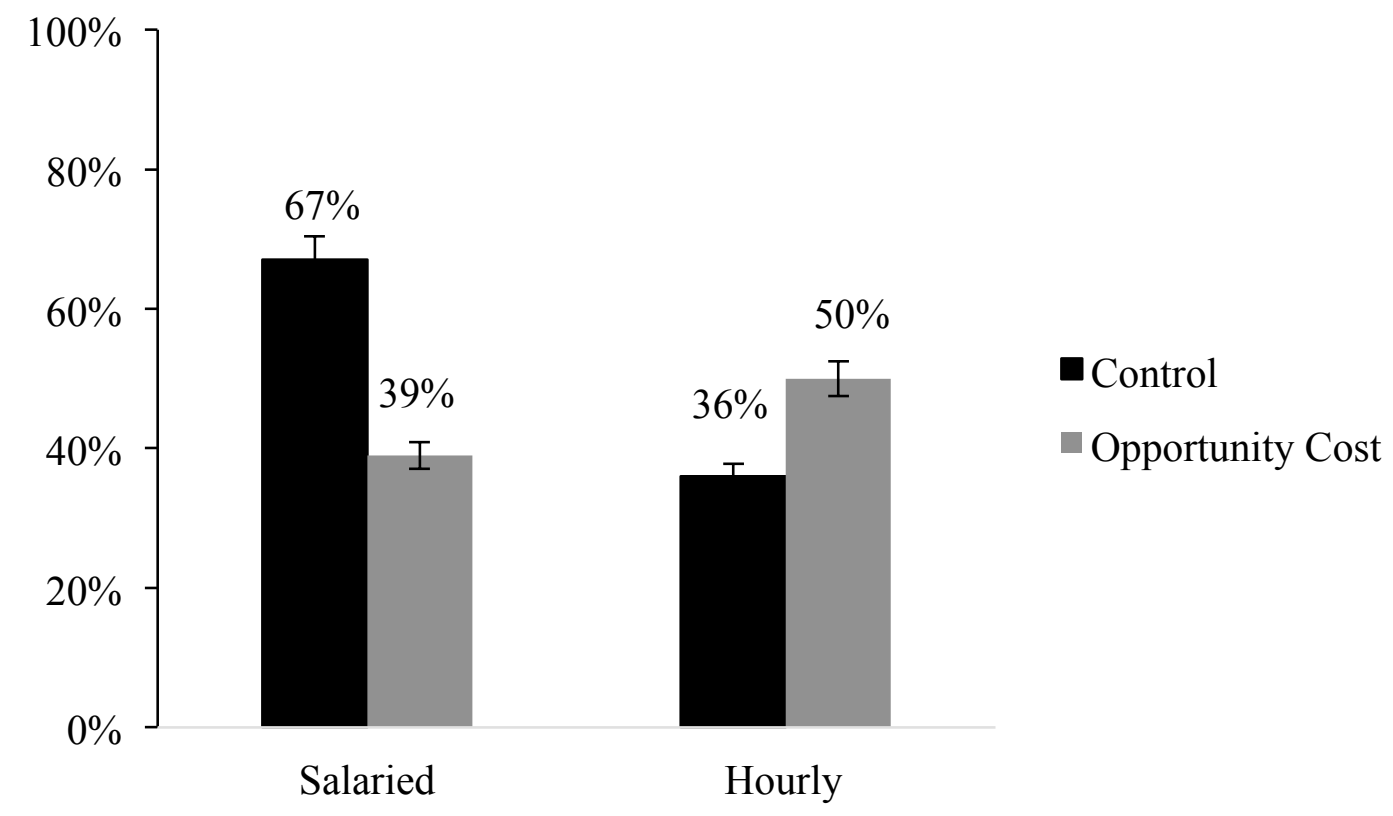




\section{REFERENCES}

Aguiar, M. \& Hurst, E. (2009). A Summary of Trends in American Time Allocation: 1965-2005. Social Indicators Research, 93(1), 57-64. doi:10.1007/s11205-008$9362-0$

Ajzen, I. (1991). The theory of planned behavior. Organizational behavior and human decision processes, 50(2), 179-211.

Allen, J. B. \& Ferrand, J. L. (1999). Environmental locus of control, sympathy, and proenvironmental behavior: A test of Geller's actively caring hypothesis. Environment and Behavior, 31(3), 338-353. doi:10.1177/00139169921972137

AFPA; American Forest and Paper Association (2010). Paper \& Paper Recovery: http://www.paperrecycles.org/statistics/paper-paperboard-recovery. (Retrieved April 2014).

Andreoni, J., Gale, W. G., Scholz, J. K. \& Straub, J. (1996). Charitable contributions of time and money. University of Wisconsin-Madison Working Paper.

Armitage, C. J. \& Conner, M. (2001). Efficacy of the theory of planned behaviour: A meta-analytic review. British journal of social psychology, 40(4), 471-499.

Bretz, R. D. \& Judge, T. A. (1994). Person-organization fit and the Theory of Work Adjustment: Implications for satisfaction, tenure, and career success. Journal of Vocational Behavior, 44(1), 32-54. doi:10.1006/jvbe.1994.1003

Brown, K. \& Kasser, T. (2005). Are psychological and ecological well-being compatible? The role of values, mindfulness, and lifestyle. Social Indicators Research, 74(2), 349-368. doi:10.1007/s11205-004-8207-8 
Bureau of Labor Statistics (2013). Characteristics of minimum wage workers; http://www.bls.gov/cps/minwage2012.pdf (Retrieved April, 2014).

Carroll, J. (2008). Time Pressures, Stress Common for Americans. Gallup Poll, 1.

Catlin, J. R. \& Wang, Y. (2013). Recycling gone bad: When the option to recycle increases resource consumption. Journal of Consumer Psychology (Elsevier Science), 23(1), 122-127. doi:10.1016/j.jcps.2012.04.001

DeVoe, S. E. \& Pfeffer, J. (2007). Hourly payment and volunteering: The effect of organizational practices on decisions about time use. Academy of Management Journal, 50(4), 783-798. doi: 10.5465/AMJ.2007.26279171

DeVoe, S. E. \& Pfeffer, J. (2007). When time is money: The effect of hourly payment on the evaluation of time. Organizational Behavior and Human Decision Processes, 104(1), 1-13. doi:10.1016/j.obhdp.2006.05.003

DeVoe, S. E. \& Pfeffer, J. (2010). The Stingy Hour: How Accounting for Time Affects Volunteering. Personality \& Social Psychology Bulletin, 36(4), 470-483. doi:10.1177/0146167209359699

DeVoe, S. E. \& Pfeffer, J. (2011). Time is tight: How higher economic value of time increases feelings of time pressure. Journal of Applied Psychology, 96(4), 665676. doi:10.1037/a0022148

Devoe, S. E., Lee, B. Y. \& Pfeffer, J. (2009). Hourly versus salaried payment and decisions about trading time and money over time. Indus. \& Lab. Rel. Rev., 63, 627.

Dutcher, D., Finley, J., Luloff, A. \& Johnson, J. (2007). Connectivity with nature as a measure of environmental values. Environment and Behavior, 39, 474-493. 
doi:10.1177/0013916506298794.

Evans, J. A., Kunda, G. \& Barley, S. R. (2004). Beach time, bridge time, and billable hours: The temporal structure of technical contracting. Administrative Science Quarterly, 49(1), 1-38.

Evans, L., Maio, G. R., Corner, A., Hodgetts, C. J., Ahmed, S. \& Hahn, U. (2012). Selfinterest and pro-environmental behaviour. Nature Climate Change, 3(2), 122125.

Ford, J., Bosworth, D. \& Wilson, R. (2006). Part-time work and full-time higher education. Studies in Higher Education, 20, 187-202. doi:10.1080/03075079512331381693

Fowler, J. H. \& Kam, C. D. (2007). Beyond the self: Social identity, altruism, and political participation. The Journal of Politics, 69(3), 813-827. doi:10.1111/j.1468-2508.2007.00577.x

Frederick, S., Novemsky, N., Wang, J., Dhar, R. \& Nowlis, S. (2009). Opportunity cost neglect. Journal of Consumer Research, 36(4), 553-561.

Geller, E. (1995). Actively caring for the environment: An integration of behaviorism and humanism. Environment and Behavior, 27(2), 184-195.

doi:10.1177/0013916595272004

Greendex (2012). Consumer choice and the environment-World survey, 2012 Report: http://www.globescan.com/component/edocman/?view=document\&id=44\&Itemi $\underline{\mathrm{d}=591}$ (Retrieved April 2014).

Grouzet, F. E., Kasser, T., Ahuvia, A., Dols, J., Kim, Y., Lau, S. \& ... Sheldon, K. M. (2005). The Structure of Goal Contents Across 15 Cultures. Journal of 
Personality and Social Psychology, 89(5), 800-816. doi:10.1037/00223514.89.5.800

Hamermesh, D. S. (2002). 12 Million Salaried Workers Are Missing. Industrial And Labor Relations Review, 55(4), 649-666.

Harrison, G. W. \& List, J. A. (2004). Field experiments. Journal of Economic Literature, 42, 1009-1055. doi:10.1257/0022051043004577

Heyman, J. \& Ariely, D. (2004). Effort for payment: A tale of two markets. Psychological Science, 15(11), 787-793. doi:10.1111/j.0956-7976.2004.00757.x

Kaveny, M. C. (2001). Billable hours in ordinary time: A theological critique of the instrumentalization of time in professional life. Loy. U. Chi. LJ, 33, 173.

Levitt, S. D. \& List, J. A. (2007). What do laboratory experiments measuring social preferences reveal about the real world? Journal of Economic Perspectives, 21(2), 153-174. doi:10.1257/jep.21.2.153

Liu, W. \& Aaker, J. (2008). The happiness of giving: The time-ask effect. Journal of Consumer Research, 35(3), 543-557. doi:10.1086/588699

Mathison, S. a. (1988). Why Triangulate?.Educational Researcher, 17(2), 13-17.

Maio, G. R., Pakizeh, A., Cheung, W. \& Rees, K. J. (2009). Changing, priming, and acting on values: Effects via motivational relations in a circular model. Journal of Personality and Social Psychology, 97(4), 699-715. doi:10.1037/a0016420

Mogilner, C., Chance, Z. \& Norton, M. I. (2012). Giving time gives you time. Psychological Science, 23(10), 1233-1238. doi:10.1177/0956797612442551

Morales, L. (2010). Green behaviors common, but not increasing. Gallup Poll, 2. 
Piff, P. K., Kraus, M. W., Côté, S., Cheng, B. \& Keltner, D. (2010). Having Less, Giving More: The Influence of Social Class on Prosocial Behavior. Journal of Personality \& Social Psychology, 99(5), 771-784. doi:10.1037/a0020092

Pfeffer, J. \& DeVoe, S. E. (2009). Economic Evaluation: The Effect of Money and Economics on Attitudes about Volunteering. Journal of Economic Psychology, 30(3), 500-508. doi:http://dx.doi.org.ezproxy.library.ubc.ca/10.1016/j.joep.2008.08.006

Prentice, D. A. \& Miller, D. T. (1992). When small effects are impressive. Psychological Bulletin, 112(1), 160.

Simmons, J. P., Nelson, L. D. \& Simonsohn, U. (2011). False-positive psychology: Undisclosed flexibility in data collection and analysis allows presenting anything as significant. Psychological Science, 22(11), 1359-1366. doi:10.1177/0956797611417632

Schwartz, S. H. (2009). Basic human values. Sociologie, 42, 249-288.

Schwartz, S. H. (1977). Normative Influences on Altruism. Advances in experimental social psychology, 10, 221-279.

Schwartz, S. H. (1992). Universals in the content and structure of values: Theory and empirical tests in 20 countries. In M. Zanna (Ed.), Advances in experimental social psychology (Vol. 25, pp. 1-65). New York: Academic Press.

Richins, M. L. \& Dawson, S. (1992). A consumer values orientation for materialism and its measurement: Scale development and validation. Journal of Consumer Research; Journal of Consumer Research. doi:10.1086/209304. 
Rick, S. I., Cryder, C. E. \& Loewenstein, G. (2008). Tightwads and spendthrifts. Journal of Consumer Research, 34(6), 767-782.

Vohs, K. D., Mead, N. L. \& Goode, M. R. (2006). The Psychological Consequences of Money. Science, 314(5802), 1154-1156. doi:10.1126/science.1132491

Vohs, K. D., Mead, N. L. \& Goode, M. R. (2008). Merely Activating the Concept of Money Changes Personal and Interpersonal Behavior. Current Directions In Psychological Science. 17(3), 208-212. doi:10.1111/j.1467-8721.2008.00576.x

Webb, T. L. \& Sheeran, P. (2006). Does Changing Behavioral Intentions Engender Behavior Change? A Meta-Analysis of the Experimental Evidence. Psychological Bulletin, 132(2), 249-268. doi:10.1037/0033-2909.132.2.249

Whillans, A.V., Caruso, E.M. \& Dunn, E.W. (2014) Agentic appeals increase giving among the affluent. Unpublished manuscript. The University of British Columbia.

Yakura, E. K. (2001). Billables The Valorization of Time in Consulting. American Behavioral Scientist, 44(7), 1076-1095.

Zelezny, L. C., Chua, P. P. \& Aldrich, C. (2000). New ways of thinking about environmentalism: Elaborating on gender differences in environmentalism. Journal of Social Issues, 56(3), 443-457. 
Appendix 1

BHPS Scale Items \& Variable Names

Environmental Scale

BHPS Name

Leaves TV on standby overnight

RGRNLFA

Switches off lights in empty rooms (R)

RGRNLFB

Lets the tap run while brushing teeth

Wears extra rather than turning up the heat $(\mathrm{R})$

RGRNLFC

Doesn't buy because of excess packaging

RGRNLFD

Buys local food

RGRNLFE

Buys recycled products

RGRNLFF

Takes own bag shopping

RGRNLFG

RGRNLFH

\section{Covariates}

Number of hours worked per week

RJBHRS

Income earned per month

RFIHHMN

Marital Status

RMLSTAT

Age

RAGE

Highest level of education

RQFEDHI

Number of own children in the home

RNCHILD

Household size

RHHSIZE

Gender

RSEX 
Appendix 2

Supplementary Materials and Results

In Studies 2 and Study 3, we asked participants to complete measures of time pressure and time scarcity. Specifically, participants rated their agreement with seven statements about feelings of time pressure (1-Strongly Disagree to 7-Strongly Agree; $\alpha=$ .91) and a 1-item question assessing the extent to which they felt that time was one of their scarcest resources (Mogilner, Chance \& Norton, 2012; 1-Strongly Disagree to 7Strongly Agree). For exploratory purposes, at the end of the survey in each study, we also asked participants to complete a 15-item measure of materialism (Richins \& Dawson, 1992; $\alpha=$.77), a 5 -item measure assessing environmental concern (Dutcher, Finley, Luloff \& Johnson, 2007; $\alpha=.69$ ). These measures were not central to the present hypothesis. Controlling for each of these additional measures studied across Studies 2, 4, and 5 did not substantively affect our central results; thus, these measures are not discussed further (We did not measure materialism or environmental concern in Study 3).

In Study 2, consistent with past research (DeVoe \& Pfeffer, 2011), participants in the hourly-wage condition $(M=4.82, S D=1.19)$ reported marginally higher levels of time pressure than participants in the control condition $(M=4.52, S D=1.10), F(1,185)=$ $3.20, p=.08, \eta 2=.02$. Participants in the hourly-wage condition $(M=5.00, S D=1.47)$ were also more likely to report that time was one of their scarcest resources compared to participants in the control condition $(M=4.46, S D=1.70), F(1,183)=5.45, p=.02, \eta^{2}=$ .03 . Our critical effects remained significant when adding time pressure and time scarcity as covariates. Controlling for time pressure, participants in the hourly-wage condition ( $M$ $=5.01, S D=.72)$ reported reduced intentions to engage in environmental behavior compared to participants in the control condition $(M=4.79, S D=.79), F(1,184)=3.73$, 
$p=.06, \eta^{2}=.02$. Similarly, controlling for time pressure, participants in the hourly-wage condition felt that engaging in environmental behaviors the year following graduation was less worthwhile $(M=5.37, S D=.89)$ compared to participants in the control condition $(M=5.06, S D=.86), F(1,180)=6.16, p=.01, \eta^{2}=.03$.Thus, although seeing time as money increased feelings of time pressure and time scarcity (in line with previous research), the effect of our manipulation on environmental intentions was not explained by feelings of time pressure.

In Study 4, participants in the hourly-wage condition $(M=4.78, S D=.89)$ reported slightly higher levels of time pressure than participants in the control condition $(M=4.43, \mathrm{SD}=1.23), F(1,51)=1.34, p=.25, \eta^{2}=.03$. Participants in the hourly-wage condition also reported slightly higher levels of time scarcity $(M=4.64, S D=1.38)$ compared to participants in the control condition $(M=4.46, S D=1.36), F(1,51)=.22, \mathrm{p}$ $=.64, \eta^{2}=.00$. However, these differences were not significant, $\mathrm{ps}>.25$, and thus could not explain the effect of condition on recycling in this experiment. 
Appendix 3

Survey Items Study 2

1. Packing my own lunch to take to work or school

2. Travelling by foot, bike or mass transit

3. Reusing ziplock bags

4. Turning off the lights in unoccupied rooms before leaving home

5. Buying locally grown food

6. Turning off car engines versus idling

7. Composting and/or recycling household waste

8. Turning off the computer vs. leaving it on standby

9. Using a travelling mug versus a disposable cup

10. Using electronic methods to pay for bills

11. Hang drying your clothes rather than using the dryer

12. Using rechargeable batteries instead of buying disposable

13. Recycling newspapers once you have read them

Buying organic food 
Appendix 4

Survey Items Study 3

1. Taking the stairs at work or school

2. Travelling by foot as opposed to driving

3. Attending fitness classes

4. Working out in the morning before starting your day

5. Buying a gym membership

6. Getting exercise during lunch breaks versus working

7. Running and/or jogging a few times every week

8. Doing your own yard work vs. hiring someone

9. Riding your bike to an appointment vs. driving

10. Finding the furthest parking spot in the lot vs. the closest

11. Planning exercise into your daily routine

12. Keeping an exercise log to monitor your physical activity

13. Exercising with friends before going out to eat

14. Buying yoga passes 
Appendix 5

Protocol Study 4

1. The Research Assistant confirms that the participant is in the lab to participate in the study "Daily Habits \& Behavior"

2. The Research Assistant will show the student(s) the consent form.

3. The Research Assistant will ask the student to read and sign the consent form.

4. The Research Assistant will remain in the same lab room in order to answer any questions pertaining to the consent form that the participant(s) might have.

5. The participant(s) will be given as much time as they request/need to read the consent form and decide whether or not they wish to participate.

6. The Research Assistant will ask the participant(s) to fill out the brief survey. Participants will be randomly assigned to fill out the Experimental or the Control Condition Survey.

7. Once the participant has completed the brief Experimental or Control Condition manipulation, the RA will tell the participant:

"Thank you for completing the first questionnaire. You will now complete a small in lab task. In this task you will cut out shapes from the pieces of paper provided to you. To ensure that you can complete the task correctly, I am providing you with the following materials. Also, are you left or right handed?"

- A stack of paper

- 2 pairs of scissors

- A pencil

- 3 Shape Tracers (Square, Triangle, Circle)

"Please use the tracers, pencil and scissors to cut 3 of each of the shapes listed above. Once you are finished with this task, you can dispose of the scrap paper in the trash here, or there is a recycling bin just outside the lab room." Please report to me (the research assistant) once you have completed the task."

If the RA comes back into the room and they see the participant hasn't thrown out the scrap paper. "I just have to go get your final questionnaire; you can put the scrap paper in the trash can or the recycling bin just outside the lab. I'll be right back."

8. Once the student is done the task, the research assistant will hand out the remaining questionnaires (i.e., environmental values survey/social values survey).

9. Students will be debriefed, thanked, and will have the opportunity to ask any questions if they so desire. 
Appendix 6

Protocol Study 5

\section{Travel Mug:}

Imagine that you have recently listened to a radio program about the importance of everyday environmental behaviors. This radio program reminded you about a simple daily action that can help the environment - using a travel mug versus a disposable cup for your favorite morning beverage (e.g., coffee). You have purchased a travel mug, but after leaving the house this morning, you realize that you have left your travel mug at home (which is about a 5 minute walk away).

\section{Can Recycling:}

Imagine that you have recently learned about the importance of everyday environmental behaviors and you are reminded about a simple daily action that can help the environment while listening to the radio - recycling your aluminum cans instead of throwing them out. You intend to recycle your aluminum can from a coke you were drinking on your way out of the office. However, the bus has arrived and while the garbage bin is on the way to the bus, the recycling bin is across the street. Recycling the can will mean waiting for the next bus (which will arrive in about 5 minutes). 